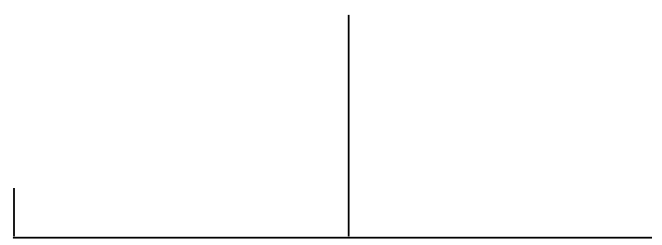

Rev. Latinoam. Psicopat. Fund., São Paulo, v. 15, n. 2, p. 382-403, junho 2012

\title{
O Hospício de Pedro II e os alienados no Brasil (1875)*
}

Philippe-Marius Rey

Uma recente viagem ao Brasil nos permitiu estudar a organização hospitalar deste país e especialmente o atendimento aos alienados. Durante a nossa estadia de um mês de duração no Rio de Janeiro, visitamos frequentemente o asilo, onde a recepção calorosa da diretoria facilitou esse estudo. O Dr. Goulart, médico chefe, teve a gentileza de desenhar um mapa das instalações. O secretário da Santa Casa da Misericórdia muito gentilmente nos forneceu os relatórios e as estatísticas de vários anos. O Sr. Diretor da casa de detenção nos mostrou em detalhes a área dessa prisão que é reservada aos criminosos alienados. Ficaríamos felizes se esses documentos e as nossas próprias observações, resumidos em uma breve apresentação, chamassem a atenção para uma instituição que já é digna de interesse, e à qual a inteligência e a preocupação da administração proporcionam um forte desenvolvimento.

No dia 10 de julho de 1841, graças à iniciativa generosa de José Clemente Pereira, ${ }^{2}$ foi publicado o decreto que ordenou a construção de um asilo no Rio de Janeiro. Sob o patrocínio do Imperador Pedro II, este asilo foi inaugurado em 1852 e foi originalmente planejado para trezentos pacientes de ambos os sexos.

* Publicação original: L'hospice Pedro II et les aliénés au Brésil. Par M. Ph. Rey, Annales médico-psychologiques, ano 33, n. 13, p. 75-98, 1875 (na seção Estabelecimentos de Alienados). Tradução de Christian Greis. Revisão técnica e notas de Manoel Olavo Teixeira.

1. "Goulard", no original. Rey refere-se ao Dr. Inacio da Silva Goulart, diretor médico do hospício de 1872 a 1876 . (N. do R.).

2. "Clémenti", no original. Rey refere-se ao Provedor da Santa Casa de Misericórdia, chamado de Mordomo de Deus, mentor e coordenador da construção do hospício de Pedro II. (N. do R.). 
O Hospício Pedro II está localizado na admirável baía de Botafogo, num bairro salubre, amplamente aberto para o mar e dominado por montanhas arborizadas. Ele é localizado numa distância conveniente do rico subúrbio de Botafogo e do terminal das linhas de bondes que atendem essa área.

Externamente, o edifício se apresenta de forma retangular, sem divisões, com um piso térreo e um primeiro andar. Esta uniformidade é interrompida apenas pela capela que domina o centro e o fundo.

A fachada frente à baía contém uma escada externa central e a porta de entrada. Nos lados, há grandes janelas simetricamente dispostas, tanto no piso térreo quanto no primeiro andar. Um jardim cercado por uma longa grade de ferro separa completamente o prédio da estrada.

Para facilitar a descrição, dividiremos o asilo em três partes: uma parte central, incluindo a administração, a capela e os atendimentos gerais; duas partes laterais, ocupadas pelos doentes.

Parte central - Na entrada, há um grande saguão decorado com duas estátuas de mármore representando Pinel e Esquirol. À esquerda se encontra a secretaria, uma única sala para o médico-chefe, o administrador e o secretário, um bengaleiro, duas salas e um depósito, uma escada que leva até o primeiro andar. À direita se encontra o consultório. No fundo do saguão, há uma escada central que leva à capela, a qual ocupa o plano superior. Duas portas laterais levam a um armazém de alimentos, ao refeitório da comunidade, às cozinhas e à farmácia. Essas diferentes partes são interligadas entre si, bem como de cada lado por uma galeria externa que as separa de um pátio com hortas.

No primeiro andar, há uma sala de recepção, um salão de honra e uma sala onde estão expostas as várias obras dos pacientes.

Partes laterais - As duas partes laterais formam duas alas simétricas que integram o edifício central. A ala esquerda é ocupada pelos homens, a ala direita pelas mulheres. No térreo, ao redor de um pátio central, há uma galeria com: 1 . do lado da fachada, seis quartos particulares, com uma ou duas camas, um dormitório, dois quartos particulares, uma sala de reuniões; 2. do lado do prédio central, há uma enfermaria para doenças intercorrentes, um dormitório para os incuráveis, uma sala para os guardas; 3. do lado livre, oito células e um dormitório; 4. os banheiros e as latrinas compõem o quarto lado. Finalmente, dois refeitórios adjacentes, um para os pensionistas e outro para os indigentes, se encontram na continuação do quarto lado e, vinculando-o aos atendimentos gerais, completam assim o retângulo formado pelo conjunto dos edifícios. As galerias ligam diretamente a parte central com as duas divisões laterais. No piso térreo se encontram os agitados, os paralíticos, os epilépticos e os idiotas.

As celas fortes são absolutamente primitivas e lembram muito a época tenebrosa da história dos asilos. Elas são compostas por uma sala bastante 
espaçosa, com paredes grossas, que está fechada do lado da galeria por uma enorme grade de ferro. Cada cela é iluminada por uma janela com grades que se encontra na parede traseira. Uma segunda grade, que se encontra um pouco mais na frente, separa um espaço ocupado pelas latrinas entre ela e o espaço ocupado pela janela. Finalmente, algumas celas são divididas em duas câmaras por uma terceira grelha transversal. A primeira câmara é ocupada pelos paralíticos senis, a segunda pelos agitados.

Todos dormem em esteiras que, pelo menos para os paralíticos, são trocadas todos os dias.

Os banhos são constituídos por: 1. a primeira sala de banhos frios, com uma grande banheira de mármore embutida no chão e três duchas de jato, de queda d'água e de chuva; 2 . uma sala de descanso; 3 . uma galeria ocupada por quatro banheiras, que também são de mármore e embutidas no chão; 4. a segunda sala para banhos medicamentosos, com uma banheira de metal esmaltado que pode ser usada para banhos de vapor devido a um duplo fundo móvel em forma de grelha.

A distribuição de água fria e quente é feita separadamente, por meio do sistema adotado nos hospícios do Sena.

O primeiro e único andar é para os doentes tranquilos, independentemente da natureza de sua afecção. As diferentes partes também estão distribuídas nos quatro lados. O lado da fachada e o lado paralelo ao prédio central possuem as mesmas divisões do piso térreo. Uma sala é ocupada pela lavanderia e outra pela biblioteca, ss celas fortes correspondem aos quartos particulares, em número de doze. Acima dos banhos, há um terraço coberto que serve de pátio onde os pacientes passeiam. É lá também onde se encontram as latrinas do primeiro andar.

Assim se compõe o asilo atual que, infelizmente, foi construído sem que a administração tenha recebido a orientação de um alienista. As diferentes partes do estabelecimento são espaçosas e arejadas, com grandes janelas de vidro, cujas estruturas são de ferro. Os dormitórios e enfermarias nunca contêm mais de 18 a vinte leitos, todos de ferro. São equipados com um colchão, lençóis e um cobertor de lã, no inverno. Os refeitórios possuem mesas de mármore e cada seção possui um local para lavar pratos e utensílios de cozinha. As latrinas são do tipo vaso sanitário. Esses são enxaguados por uma corrente intermitente de água. A iluminação ocorre por gás.

A administração logo percebeu que esse asilo não era suficiente e que seu plano continha várias falhas. Novos edifícios estão sendo construídos atualmente ao lado dos banhos. Cada sexo terá sua própria ala, com um piso térreo, um primeiro andar e um pátio central. O asilo assumirá então a forma de uma ferradura.

A principal mudança desse novo plano é a criação de uma seção inteira para os agitados, que ocupa o andar térreo. Ela é composta da seguinte maneira: 1. 
duas fileiras de quartos, separadas por um corredor, para os semiagitados; 2 . dez a 12 celas mais convenientes que as antigas; essas serão removidas e o lado que elas ocupam será utilizado para os pacientes imundos. Uma enfermaria, um refeitório, uma sala de reuniões, banhos e latrinas completarão as partes essenciais dessa seção. Um pátio central será reservado para os semiagitados. $\mathrm{Na}$ frente das celas haverá um jardim e do outro lado dele, haverá cinco ou seis gramados pequenos, um para cada dois agitados.

O primeiro andar será reservado aos doentes tranquilos. Ele incluirá quartos particulares, dormitórios e uma sala de reuniões. Acima das celas, um terraço coberto será usado para o seu monitoramento, através de vigias. Estes novos edifícios providenciarão aproximadamente 250 lugares para ambos os sexos, permitirão isolar melhor os agitados e deixarão, nos prédios antigos, um lugar que pode ser utilizado. Mas é difícil adaptar um edifício que foi construído com base num plano com defeitos a todas as necessidades de um atendimento assistencial dessa natureza. Sempre haverá algum defeito inerente a sua primeira organização.

Um único asilo, na capital, por melhor instalado e completo que seja, não será suficiente no Brasil, tanto por causa da quantidade de alienados quanto por causa da extensão do Império e as dificuldades de transporte. Assim, asilos provinciais estão sendo construídos na Bahia, em Pernambuco e em São Paulo.

Acrescentamos que no Rio de Janeiro, várias casas de saúde recebem os alienados em departamentos adequadamente preparados para essa finalidade.

\section{Administração - Funcionários}

Existe no Rio de Janeiro uma instituição de caridade que administra todos os hospitais e asilos da capital. É a Santa Casa da Misericórdia. Essa associação se assemelha à nossa assistência pública. Suas receitas são importantes e provêm em parte dos impostos sobre as loterias, dos serviços funerários, dos impostos alfandegários e principalmente de legados em forma de propriedades e capital feitos por pessoas que merecem todo o reconhecimento de seus concidadãos.

De acordo com o decreto de sua fundação, o Hospício Pedro II é administrado por um comitê de três membros dessa associação, com um presidente que é sempre o Provedor ou o presidente da Sociedade. Uma parte dos fundos foi especificamente destinada à sua manutenção.

O pessoal superior do Hospício é composto por um administrador, dois médicos, um dos quais é médico-chefe, um médico-assistente responsável pela consulta de pacientes externos, um suplente do médico ausente, uma irmã superior e um capelão. O serviço de farmácia é atribuído a uma irmã. 
Não há médicos internos. Essa lacuna é especialmente lamentável tendo em vista que nenhum membro laico do pessoal superior reside no Hospício. Portanto, durante a maior parte do dia e durante toda a noite, a gestão do estabelecimento está nas mãos da madre superiora, à qual o regulamento confere um alto grau de autoridade.

Há, porém, uma escola de medicina no Rio de Janeiro e temos certeza de que a função de médico interno, com seus benefícios apropriados, será procurada por muitos jovens dispostos a se dedicar ao estudo das doenças mentais.

Vinte irmãs de São Vicente de Paulo trabalham nos atendimentos gerais. Elas são responsáveis pela supervisão e execução de prescrições médicas em ambas as divisões e recebem a ajuda de enfermeiras e enfermeiros. As enfermeiras são selecionadas entre as jovens órfãs que foram recolhidas e educadas pelo Hospício. Há um enfermeiro para cada 25 pacientes. $\mathrm{O}$ atendimento noturno funciona em ambas as divisões.

$\mathrm{Na}$ opinião dos médicos, os enfermeiros deixam muito a desejar, mas a sua negligência e erros são severamente punidos, e os maus-tratos aos pacientes resultam na expulsão imediata do infrator, e, se o caso for grave, pode até ser julgado pelos tribunais. Essas medidas, que são altamente louváveis, refletem o espírito de humanidade que preside a organização do atendimento.

\section{Internação e alta dos pacientes}

Não existe no Brasil, propriamente dita, nenhuma legislação para reger os alienados. Estatutos apresentados por José Clemente Pereira e aprovados pelo governo determinam o modo de internação dos alienados, o processo de alta, e são suficientes para prevenir abusos.

As internações são voluntárias ou oficiais. As internações voluntárias, tanto no asilo público quanto em casas particulares, requerem um pedido do pai, tutor ou curador, irmão, irmã, marido ou esposa, ou proprietário do alienado, com a sua firma reconhecida por um magistrado e o certificado de um médico que também deve ser aprovado pelas autoridades.

As internações oficiais são feitas a partir de uma requisição do presidente do orfanato (juiz dos órfãos) ou do chefe da polícia, seja do distrito do alienado, seja do local onde ele foi preso.

Para os militares, clérigos ou religiosos, essa requisição é emitida pelos seus superiores correspondentes. Todos os pedidos ou requisições são endereçados ao provedor, que é o único que pode autorizar a internação.

Em caso de urgência, o provedor pode ordenar a admissão do alienado, sem que as formalidades tenham sido cumpridas. Nesse caso, os alienados 
permanecem sob observação por um período não superior a 15 dias. Em todos os casos, o médico do estabelecimento deve apresentar um certificado segundo o qual o provedor ordena ou a sua permanência, ou a sua alta.

Os membros da Comissão inspecionam o asilo com bastante frequência.

A alta do alienado é apenas autorizada após a sua recuperação completa e com um atestado médico, exceto para os pensionistas que podem ser removidos independentemente do seu estado mental. A alta de qualquer pessoa pode apenas ocorrer após o provedor ter avisado as autoridades.

Como constatamos, essas disposições legais são baseadas na nossa lei de 1838.

\section{População}

O número aproximado dos alienados conhecido em todo o Império é de 15.000 para uma população de 11.780 .000 habitantes.

O número de vagas no asilo do Rio de Janeiro é de trezentos. Esse número é às vezes aumentado até 349 . O número insuficiente de vagas e o transporte difícil dos alienados que residem distantes da capital resultaram na impossibilidade de a maioria dos pacientes receberem os tratamentos na fase aguda de sua doença e numa grande quantidade de doentes crônicos no asilo.

A população é constituída de indigentes e pensionistas. São admitidos gratuitamente: os indigentes, os marinheiros dos navios mercantes, os escravos de proprietários que apenas possuam um único escravo.

Os alienados que podem arcar com os custos de sua estadia são admitidos como pensionistas. Os soldados do exército e da marinha e os associados da Santa Casa da Misericórdia, sem recursos suficientes, são admitidos gratuitamente numa das classes de pensionistas.

Existem três classes de pensionistas. O preço da pensão para a primeira classe é de 5.000 réis, ou seja, cerca de 15 francos por dia; para a segunda classe, ela é de 3.000 réis, ou de 9 francos; e de 1.600 a 2.000 réis ou 5 a 6 francos para os doentes de terceira classe.

Os pensionistas de $1^{\mathrm{a}}$ e $2^{\mathrm{a}}$ classes ocupam quartos particulares com uma ou duas camas e tem um refeitório especial. Sua dieta consiste em: 1. café da manhã: pão branco, chá ou café com leite, açúcar e manteiga; 2. almoço: pão, sopa de pão, carne bovina cozida, arroz, frango, toucinho, legumes ou salada, vinho, frutas e compotas; 3. jantar: pão, chá ou café com leite, açúcar e manteiga.

Os indigentes e pensionistas de $3^{\text {a }}$ classe compartilham os mesmos dormitórios e refeitórios e a mesma dieta, que consiste de: 1. café da manhã: pão 
branco, chá ou café, leite, açúcar e manteiga; 2. almoço: pão, sopa de pão, carne bovina, toucinho, arroz e frutas; 3. jantar: pão, chá, café, leite, açúcar e manteiga. A dieta dos indigentes e pensionistas pode às vezes variar. Substitui-se o pão, a carne bovina e o arroz pela farinha de mandioca, pela carne seca e pelo feijão, alimentos cujo uso é muito difundido.

A dieta da enfermaria, prescrita por cada supervisor de departamento, é a mesma dos pacientes do Hospital da Misericórdia.

Visitamos a despensa, que está bem abastecida com alimentos de boa qualidade; e a preparação dos alimentos, feita por meio de fogões, nos pareceu bem cuidada.

\section{Relatórios estatísticos}

A disposição dos edifícios, como vimos, não se presta a uma boa distribuição dos pacientes. A única divisão, tanto nos homens quanto nas mulheres, é a divisão entre os alienados agitados e os paralíticos, no térreo, e os alienados tranquilos, no $1^{\circ}$ andar. Os pensionistas e indigentes, os livres e escravos, são classificados nessas duas categorias.

Todo ano, o diretor-médico tem a obrigação de apresentar um relatório à administração sobre o estado do asilo, sua organização e as modificações consideradas necessárias. Esse relatório é seguido por uma estatística que demonstra o movimento da população do asilo. Esses relatórios anuais mostram que os autores possuem um profundo conhecimento dos progressos feitos nas grandes instituições da Europa. Eles apontam para as reformas necessárias, tanto nos aspectos físicos do edifício quanto em sua organização interna: a criação de departamentos especiais para os agitados, epilépticos e idiotas, a criação de um pensionato, a criação de um departamento para os incuráveis e enfermos que superlotam o asilo atual, expandir as possibilidades de trabalho dos alienados através da criação de oficinas e de uma fazenda nos vastos terrenos que pertencem ao asilo. Eles insistem especialmente na necessidade de pessoal médico-residente no asilo.

As estatísticas mostram o movimento da população de $1^{\circ}$ de julho de cada ano até 30 de junho do próximo ano e incluem, na primeira tabela, a população em $1^{\circ}$ de julho, o número de admissões, altas, mortes e a população em 30 de junho.

A segunda tabela fornece os números dos alienados que saíram por nacionalidade e idade, com a indicação da doença e tempo de permanência no asilo.

A terceira tabela apresenta o número de mortes por nacionalidade, por idade, com a causa da morte e do tempo de permanência no asilo.

Finalmente, a quarta tabela se refere aos alienados que permanecem no asilo em 30 de junho. 
Representamos aqui o movimento geral da população de 1869 a 1870 e de 1873 a $1874^{(1)}$.

TABELA I. Movimento dos alienados do Hospício Pedro II de 1869 a 1870 (de $1^{\circ}$ de julho 1869 a 30 de junho de 1870)

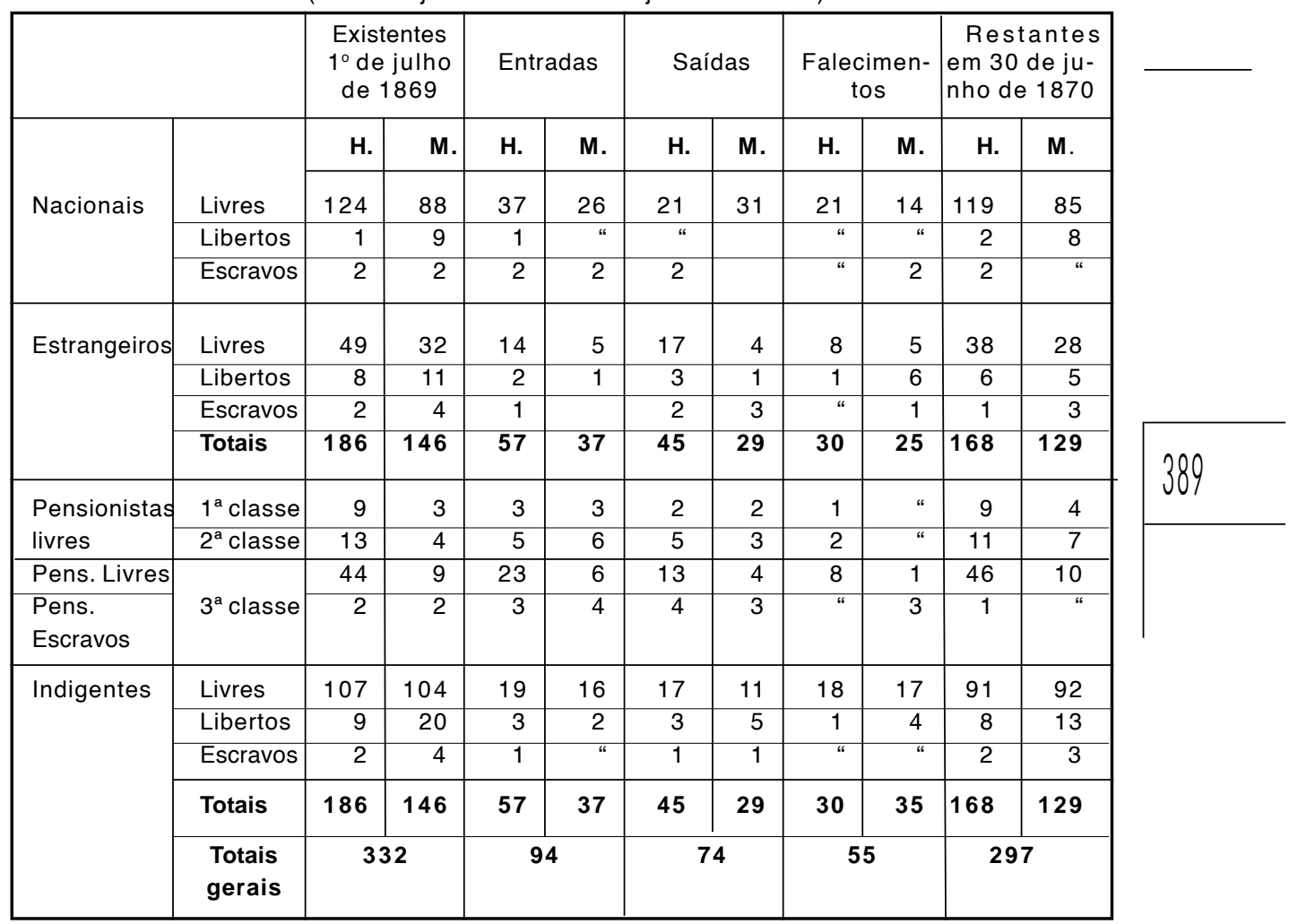

(1) As estatísticas de 1869 a 1870 foram compiladas pelo Sr. Dr. Barbosa, ${ }^{3}$ ex-médico chefe do asilo; as de 1873-1874, pelo Sr. Dr. Goulart. Reformulamos várias tabelas publicadas para facilitar sua leitura.

3. Rey refere-se ao Dr. Manoel José Barbosa, diretor-médico do hospício de 1853 a 1866 (N. do R.) 
TABELA II - Movimento dos alienados do Hospício Pedro II, de 1873 a 1874

\begin{tabular}{|c|c|c|c|c|c|c|c|c|c|c|c|}
\hline & & \multicolumn{2}{|c|}{$\begin{array}{l}\text { Existentes } \\
1^{\circ} \text { de julho } \\
\text { de } 1873\end{array}$} & \multicolumn{2}{|c|}{ Entradas } & \multicolumn{2}{|c|}{ Saídas } & \multicolumn{2}{|c|}{ Falecimentos } & \multicolumn{2}{|c|}{$\begin{array}{l}\text { Restantes } \\
\text { em } 30 \text { de } \\
\text { junho } \\
\text { de } 1874\end{array}$} \\
\hline & & H. & M. & H. & M. & H. & M. & H. & M. & H. & M \\
\hline \multirow[t]{3}{*}{ Nacionais } & Livres & 111 & 83 & 40 & 24 & 15 & 10 & 21 & 18 & 115 & 79 \\
\hline & Libertos & 3 & 6 & 1 & 6 & 1 & $"$ & $"$ & 1 & 3 & 11 \\
\hline & Escravos & 1 & “ & “ & “ & “ & “ & “ & “ & 1 & “ \\
\hline \multirow[t]{4}{*}{ Estrangeiros } & Livres & 43 & 33 & 16 & 9 & 7 & 4 & 7 & 6 & 45 & 32 \\
\hline & Libertos & 6 & 5 & 4 & 1 & “ & 1 & 3 & 2 & 7 & 3 \\
\hline & Escravos & 2 & 4 & 2 & “ & 2 & 1 & “ & 1 & 2 & 2 \\
\hline & Totais & 166 & 131 & 63 & 40 & 25 & 16 & 31 & 28 & 173 & 127 \\
\hline \multirow{2}{*}{$\begin{array}{l}\text { Pensionistas } \\
\text { livres }\end{array}$} & $1^{\text {a }}$ classe & 6 & 4 & 7 & 2 & 2 & 2 & “ & 1 & 1 & 3 \\
\hline & $2^{\mathrm{a}}$ classe & 15 & 9 & 5 & 1 & 5 & 2 & 1 & 2 & 1 & 6 \\
\hline \multirow{2}{*}{$\begin{array}{l}\text { Pens. Livres } \\
\text { Pens. escravos }\end{array}$} & \multirow[t]{2}{*}{$3^{a}$ classe } & 61 & 30 & 22 & 9 & 4 & 2 & 11 & 5 & 68 & 33 \\
\hline & & 1 & 1 & 2 & $"$ & 2 & 1 & 1 & " & 1 & “ \\
\hline \multirow[t]{5}{*}{ Indigentes } & Livres & 71 & 74 & 23 & 21 & 10 & 7 & 15 & 6 & 68 & 73 \\
\hline & Libertos & 9 & 10 & 5 & 7 & 2 & 2 & 3 & 3 & 9 & 9 \\
\hline & Escravos & 3 & 3 & $"$ & $"$ & " & $"$ & “ & 11 & 1 & 3 \\
\hline & Totais & 166 & 131 & 63 & 40 & 25 & 16 & 31 & 28 & 173 & 127 \\
\hline & $\begin{array}{l}\text { Totais } \\
\text { gerais }\end{array}$ & \multicolumn{2}{|c|}{297} & \multicolumn{2}{|c|}{103} & \multicolumn{2}{|c|}{41} & \multicolumn{2}{|c|}{59} & \multicolumn{2}{|c|}{300} \\
\hline
\end{tabular}

De acordo com as estatísticas sobre o movimento da população de $1^{\circ}$ de julho de 1866 a 30 de junho de 1874, ou seja, por um período de nove anos, vemos que a população média do asilo foi de 309, dos quais 174,4 homens e 134,6 mulheres.

Os brasileiros são representados, em média, por 215,5 pacientes: 121,2 homens e 94,3 mulheres.

Para os estrangeiros, a média é de 93,6, dos quais 53,3 homens e 40,3 mulheres.

O total das três classes de pensionistas resulta num valor médio de 104,76 homens e 28 mulheres.

A média dos indigentes é de 210, dos quais 104 homens e 106 mulheres. 
Finalmente, a população escrava e liberta representa uma média de 28,8 pacientes, sendo 12,2 homens e 16,6 mulheres.

O exame dos dados utilizados para o cálculo dessas médias mostra que o número de pessoas sofreu pequenas variações desde 1866.

Os totais gerais são de 349 para este mesmo ano e 275 para o próximo ano. Deve-se levar em consideração que houve, durante esse período, uma grande epidemia de cólera.

A quantidade de homens é sempre maior que a quantidade de mulheres. $\mathrm{O}$ total de pensionistas, que foi cerca de um quarto da população em 1869 , representava a metade dela entre 1873 e 1874.

A população negra - escravos e libertos - é sempre muito menor do que a população branca. Nota-se que ela diminui quase todos os anos. Ela foi de 42 pacientes em 1866 e é atualmente de 29. As mulheres dessa raça parecem mais frequentemente afetadas do que os homens.

Seguem-se várias tabelas sobre a população em 30 de junho de 1874.

TABELA III - Nacionalidade dos alienados existentes em 30 de junho 1874

\begin{tabular}{|l|c|c|c|}
\hline & Homens & Mulheres & Ambos os sexos \\
\hline Brasileiros & 119 & 90 & 209 \\
\hline Portugueses & 26 & 18 & 44 \\
\hline Franceses & 4 & 1 & 5 \\
\hline Espanhóis & 1 & 3 & 4 \\
\hline Italianos & 3 & 2 & 5 \\
\hline Americanos & 2 & " & 2 \\
\hline Africanos & 12 & 8 & 20 \\
\hline Chineses & 1 & 4 & 1 \\
\hline Alemães & 4 & 1 & 1 \\
\hline Dinamarqueses & 1 & " & 1 \\
\hline Ingleses & $\mathbf{1 7 3}$ & $\mathbf{1 2 7}$ & $\mathbf{3 0 0}$ \\
\hline Totais & & & \\
\hline
\end{tabular}


TABELA IV - Idade dos alienados existentes em 30 de junho 1874

\begin{tabular}{|l|c|c|c|}
\hline & Homens & Mulheres & Ambos os sexos \\
\hline 10 a 20 anos & 2 & 6 & 8 \\
\hline 20 a 30 anos & 17 & 20 & 37 \\
\hline 30 a 40 anos & 49 & 29 & 78 \\
\hline 40 a 50 anos & 44 & 26 & 70 \\
\hline 50 a 60 anos & 25 & 17 & 42 \\
\hline 60 a 70 anos & 7 & 9 & 16 \\
\hline 70 a 80 anos & 3 & 2 & 44 \\
\hline Idade desconhecida & 26 & 18 & 300 \\
\hline Totais & $\mathbf{1 7 3}$ & $\mathbf{1 2 7}$ & \\
\hline
\end{tabular}

TABELA V - Doenças dos alienados existentes em 30 de junho

\begin{tabular}{|l|c|c|c|}
\hline & Homens & Mulheres & Ambos os sexos \\
\hline Demência & 78 & 40 & 118 \\
\hline Mania & 28 & 33 & 61 \\
\hline Monomania & 41 & 12 & 53 \\
\hline Lipemania & 10 & 16 & 26 \\
\hline Epilepsia & 4 & 4 & 8 \\
\hline Alucinações & 4 & 1 & 5 \\
\hline Imbecilidade & 3 & 4 & 1 \\
\hline Idiotismo & 1 & $“$ & 3 \\
\hline Loucura paralítica & 3 & 27 & 300 \\
\hline Sem diagnóstico & 1 & $\mathbf{1 2 7}$ & 300 \\
\hline Totais & $\mathbf{1 7 3}$ & & \\
\hline
\end{tabular}


TABELA VI - Tempo de permanência no Hospício para os alienados existentes em 30 de junho de 1874

\begin{tabular}{|l|c|c|c|}
\hline & Homens & Mulheres & Ambos os sexos \\
\hline 20 a 25 anos & 2 & 1 & 3 \\
\hline 17 a 20 anos & 6 & 4 & 10 \\
\hline 14 a 17 anos & 10 & 8 & 18 \\
\hline 11 a 14 anos & 12 & 13 & 22 \\
\hline 8 a 11 anos & 14 & 8 & 25 \\
\hline 5 a 8 anos & 20 & 21 & 41 \\
\hline 1 a 5 anos & 66 & 45 & 111 \\
\hline 6 a 12 meses & 18 & 7 & 25 \\
\hline 1 a 6 meses & 15 & 20 & 2 \\
\hline 10 a 30 dias & 2 & 127 & 300 \\
\hline Totais & 173 & & \\
\hline
\end{tabular}

Entradas

A média das entradas entre $1^{\circ}$ de julho de 1866 até 30 de junho de 1874 foi de 129,9 pacientes, 80,9 homens e 49 mulheres. A cada ano, os números anuais sofreram algumas variações bastante expressivas, mas os autores dos relatórios não indicam a causa desse fenômeno.

\section{Saídas}

Seguem-se as tabelas dos alienados que deixaram o asilo em 1869-1870 e em 1873-1874. 
TABELA VII - Nacionalidade dos alienados que deixaram o Hospício nos anos 1869-1870 e 1873-1874

\begin{tabular}{|c|c|c|c|c|}
\hline & \multicolumn{2}{|c|}{1869 a 1870} & \multicolumn{2}{|c|}{1873 a 1874} \\
\hline & Homens & Mulheres & Homens & Mulheres \\
\hline Brasileiros & 23 & 21 & 16 & 10 \\
\hline Portugueses & 10 & 3 & 5 & 3 \\
\hline Ingleses & 2 & $"$ & 1 & " \\
\hline Franceses & 1 & “ & 1 & “ \\
\hline Africanos & 3 & 4 & 1 & 2 \\
\hline Chineses & $"$ & 1 & $"$ & “ \\
\hline Italianos & 3 & “ & “ & " \\
\hline Buenos Aires & 1 & $"$ & “ & “ \\
\hline Paraguaios & 2 & “ & “ & “ \\
\hline Alemães & " & “ & 2 & 1 \\
\hline Totais & \multicolumn{2}{|c|}{74} & \multicolumn{2}{|c|}{41} \\
\hline
\end{tabular}

TABELA VIII - Idade dos alienados que deixaram o Hospício nos anos 1869-1870 e 1873-1874

\begin{tabular}{|l|c|c|c|c|}
\hline \multirow{2}{*}{} & \multicolumn{2}{|c|}{1869 a 1870} & \multicolumn{2}{c|}{1873 a 1874 } \\
\cline { 2 - 5 } & Homens & Mulheres & Homens & Mulheres \\
\hline De 10 a 20 anos & 4 & 3 & 3 & 5 \\
\hline 20 a 30 anos & 21 & 11 & 6 & 3 \\
\hline 30 a 40 anos & 11 & 3 & 7 & 3 \\
\hline 40 a 50 anos & 5 & 6 & 7 & 4 \\
\hline 50 a 60 anos & 2 & 4 & 2 & 1 \\
\hline 60 a 70 anos & 1 & 2 & " & " \\
\hline 70 a 80 anos & 1 & 74 & & 41 \\
\hline Totais & \multicolumn{2}{|c}{74} & & \\
\hline
\end{tabular}


HISTÓRIA DA

PSIQUIATRIA

TABELA IX - Doenças dos alienados que deixaram o Hospício nos anos 1869-1870 e 1873-1874

\begin{tabular}{|c|c|c|c|c|}
\hline & \multicolumn{2}{|c|}{1869 a 1870} & \multicolumn{2}{|c|}{1873 a 1874} \\
\hline & Homens & Mulheres & Homens & Mulheres \\
\hline Alucinações & 10 & 3 & 2 & “ \\
\hline Mania & 20 & 8 & 8 & 6 \\
\hline Monomania & 2 & 2 & 5 & 1 \\
\hline Demência & 1 & 1 & 1 & “ \\
\hline Imbecilidade & 4 & 2 & “ & “ \\
\hline Lipemania & 2 & 1 & 1 & 4 \\
\hline Alcoolismo & 3 & “ & “ & 1 \\
\hline Epilepsia & 1 & “ & " & “ \\
\hline Loucura puerperal & “ & 3 & “ & “ \\
\hline Loucura histérica & “ & 5 & “ & 2 \\
\hline Sem diagnóstico & 2 & 4 & 6 & “ \\
\hline Hemiplegia & “ & “ & “ & 1 \\
\hline Tifomania & “ & “ & 1 & “ \\
\hline Mania periódica & “ & “ & 1 & 1 \\
\hline Totais & \multicolumn{2}{|c|}{74} & \multicolumn{2}{|c|}{41} \\
\hline
\end{tabular}

TABELA X - Tempo de permanência no Hospício dos alienados que o deixaram nos anos 1869-1870 e 1873-1874

\begin{tabular}{|c|c|c|}
\hline & \multicolumn{2}{|c|}{1869 a 1870} \\
\hline & Homens & Mulheres \\
\hline De 6 a 10 anos & “ & “ \\
\hline 4 a 7 anos & 3 & 2 \\
\hline 3 a 4 anos & 3 & 2 \\
\hline 1 a 3 anos & 8 & 4 \\
\hline 8 a 11 meses & 6 & 5 \\
\hline 6 a 8 meses & 5 & 6 \\
\hline 4 a 6 meses & 4 & 1 \\
\hline 2 a 4 meses & 10 & 7 \\
\hline 1 a 2 meses & 4 & 1 \\
\hline 15 a 30 dias & 3 & “ \\
\hline 1 a 15 dias & “ & 1 \\
\hline Total & \multicolumn{2}{|c|}{74} \\
\hline
\end{tabular}

Rev. Latinoam. Psicopat. Fund., São Paulo, v. 15, n. 2, p. 382-403, junho 2012 


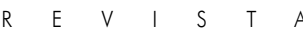

LATINOAMERICANA

DE PSICOPATOLOGIA

F U D A M E T A L

\begin{tabular}{|l|c|c|}
\hline \multirow{2}{*}{} & \multicolumn{2}{|c|}{1873 a 1874} \\
\cline { 2 - 3 } & Homens & Mulheres \\
\hline De 6 a 10 anos & 2 & 1 \\
\hline 3 a 6 anos & 3 & 3 \\
\hline 1 a 3 anos & 5 & 4 \\
\hline 6 a 12 meses & 7 & 3 \\
\hline 1 a 6 meses & 8 & 5 \\
\hline Total & \multicolumn{2}{|c|}{$\mathbf{4 1}$} \\
\hline
\end{tabular}

A média das saídas foi de 76 pacientes, 47,8 homens e 18,2 mulheres.

A comparação entre a população dos pacientes que deixaram o Hospício e a população anual resulta em:

$$
\begin{aligned}
& 3,8 \text { por } 10 \text { em } 1866-1867 . \\
& 3,0 \text { por } 10 \text { em } 1868-1869 . \\
& 3,0 \text { por } 10 \text { em } 1869-1870 . \\
& 1,6 \text { por } 10 \text { em } 1870-1871 . \\
& 1,4 \text { por } 10 \text { em } 1873-1874 .
\end{aligned}
$$

Infelizmente, os autores das estatísticas não indicam o estado mental dos alienados na alta. Portanto, torna-se impossível elaborar o número de curas.

\section{Mortalidade}

A média das mortes foi de 78,8 pacientes: 46,2 homens e 32,6 mulheres.

A proporção para cada ano foi de:

4,8 por 10 em $1866-1867$.

4,0 por 10 em $1867-1868$.

1,3 por 10 em $1869-1870$.

1,5 por 10 em $1870-1871$.

1,9 por 10 em $1873-1874$. 
HISTÓRIA DA

PSIQUIATRIA

TABELA XI - Nacionalidade dos alienados que faleceram nos anos 1869-1870 e 1873-1874

\begin{tabular}{|c|c|c|c|c|}
\hline & \multicolumn{2}{|c|}{1869 a 1870} & \multicolumn{2}{|c|}{1873 a 1874} \\
\hline & Homens & Mulheres & Homens & Mulheres \\
\hline Brasileiros & 21 & 13 & 21 & 19 \\
\hline Portugueses & 7 & 4 & 4 & 2 \\
\hline Franceses & “ & 1 & 1 & 1 \\
\hline Ingleses & “ & 1 & “ & “ \\
\hline Alemães & " & 1 & 1 & 1 \\
\hline Africanos & 2 & 5 & 1 & 4 \\
\hline Espanhóis & “ & “ & 1 & 1 \\
\hline Italianos & " & " & 1 & " \\
\hline Paraguaios & “ & $"$ & 1 & “ \\
\hline Totais & \multicolumn{2}{|c|}{55} & \multicolumn{2}{|c|}{59} \\
\hline
\end{tabular}

TABELA XII - Idade dos alienados que faleceram nos anos 1869-1870 e 1873-1874

\begin{tabular}{|c|c|c|c|c|}
\hline & \multicolumn{2}{|c|}{1869 a 1870} & \multicolumn{2}{|c|}{1873 a 1874} \\
\hline & Homens & Mulheres & Homens & Mulheres \\
\hline De 10 a 20 anos & “ & “ & 1 & 2 \\
\hline 20 a 30 anos & 7 & 4 & 8 & 5 \\
\hline 30 a 40 anos & 12 & 8 & 10 & 4 \\
\hline 40 a 50 anos & 5 & 8 & 7 & 8 \\
\hline 50 a 60 anos & 4 & 2 & 5 & 5 \\
\hline 60 a 70 anos & 2 & 1 & 1 & 2 \\
\hline 70 a 80 anos & “ & 2 & “ & 1 \\
\hline Idade desconhecida & “ & “ & “ & 1 \\
\hline Totais & \multicolumn{2}{|c|}{55} & \multicolumn{2}{|c|}{59} \\
\hline
\end{tabular}

Rev. Latinoam. Psicopat. Fund., São Paulo, v. 15, n. 2, p. 382-403, junho 2012 
TABELA XIII - Doenças que causaram o falecimento dos alienados nos anos 1869-1870 e 1873-1874.

\begin{tabular}{|c|c|c|c|c|}
\hline & \multicolumn{2}{|c|}{1869 a 1870} & \multicolumn{2}{|c|}{1873 a 1874} \\
\hline & Homens & Mulheres & Homens & Mulheres \\
\hline Marasmo & 4 & 3 & “ & 1 \\
\hline Paralisia geral & 5 & 3 & “ & “ \\
\hline Diarreia & 6 & 4 & 9 & 4 \\
\hline Lesão do coração & 1 & 1 & “ & 2 \\
\hline Tubérculos pulmonares & 3 & 1 & 2 & 7 \\
\hline Anasarca & 1 & “ & " & " \\
\hline Epilepsia & 1 & “ & “ & “ \\
\hline Hidropisia & 1 & “ & “ & “ \\
\hline Gangrena & 1 & 1 & " & 1 \\
\hline Pneumonia & 1 & “ & “ & 1 \\
\hline Apoplexia cerebral & 2 & 2 & 2 & 1 \\
\hline Caquexia palustre & 1 & “ & " & " \\
\hline Gastrenterite & 2 & 3 & " & " \\
\hline Enterocolite & 1 & “ & 2 & “ \\
\hline Meningoencefalite & “ & 2 & 3 & “ \\
\hline Meningite & “ & 1 & " & " \\
\hline Febre tifoide & “ & 2 & “ & 1 \\
\hline Anemia & “ & 1 & 1 & 1 \\
\hline Câncer de útero & “ & 1 & “ & " \\
\hline Febre adinâmica & “ & “ & “ & 1 \\
\hline Escrófulas & “ & “ & “ & 1 \\
\hline Ulcerações intestinais & “ & “ & 4 & 2 \\
\hline Derrame seroso cerebral & “ & “ & 1 & " \\
\hline Tubérculos mesentéricos & “ & “ & 1 & 1 \\
\hline Ascite & “ & “ & 2 & “ \\
\hline Congestão cerebral & “ & “ & “ & 1 \\
\hline Linfangite & " & “ & “ & 1 \\
\hline Disenteria & “ & “ & 1 & " \\
\hline Enterite & " & " & " & 1 \\
\hline Amolecimento cerebral & “ & “ & 1 & “ \\
\hline Encefalite & “ & “ & 1 & “ \\
\hline Colite & “ & “ & 1 & " \\
\hline Meningite cerebroespinhal & “ & “ & 1 & “ \\
\hline Totais & \multicolumn{2}{|c|}{55} & \multicolumn{2}{|c|}{59} \\
\hline
\end{tabular}


HISTÓRIA DA

PSIQUIATRIA

TABELA XIV - Tempo de permanência dos alienados que faleceram nos anos $1869-1870$ e 1873-1874

\begin{tabular}{|c|c|c|c|c|c|}
\hline & \multicolumn{2}{|c|}{1869 a 1870} & & \multicolumn{2}{|c|}{1873 a 1874} \\
\hline & Homens & Mulheres & & Homens & Mulheres \\
\hline 23 anos & 2 & “ & 15 a 20 anos & 2 & “ \\
\hline 12 a 15 anos & 2 & 2 & 10 a 15 anos & 3 & 3 \\
\hline 6 a 12 anos & 3 & 2 & 6 a 10 anos & 2 & 5 \\
\hline 1 a 6 anos & 4 & 9 & 1 a 10 anos & 10 & 11 \\
\hline 8 a 10 meses & 1 & 3 & 6 a 11 meses & 1 & 3 \\
\hline 4 a 8 meses & 5 & 8 & 1 a 6 meses & 7 & 5 \\
\hline 1 a 4 meses & 7 & 3 & 15 a 40 dias & 4 & 1 \\
\hline 10 a 29 dias & 2 & 2 & \multirow[t]{2}{*}{1 a 15 dias } & \multirow[t]{2}{*}{2} & \multirow[t]{2}{*}{ “ } \\
\hline 6 a 10 dias & $"$ & 1 & & & \\
\hline Totais & \multicolumn{2}{|c|}{55} & & \multicolumn{2}{|c|}{59} \\
\hline
\end{tabular}

As causas dos óbitos são indicadas para cada ano. Trata-se geralmente de doenças intercorrentes, para as quais existe, em cada divisão, um registro onde são anotadas as observações diárias.

Mencionaremos, por ordem de frequência, a diarreia, as afecções intestinais, a tísica, a apoplexia cerebral, a febre tifoide, a pneumonia, as lesões do coração, as febres perniciosas.

De 1869 a 1870, as causas de óbito incluíram oito casos de paralisia geral, sendo cinco homens e três mulheres.

A epidemia de cólera que grassava no Rio de Janeiro em 1867 se manifestou também no asilo. O número de mortes, nesse ano, é muito maior do que nos anos subsequentes.

A epidemia atingiu o asilo de 22 de fevereiro até 4 de abril. Dos 275 pacientes, 190 foram atingidos, 68 morreram, incluindo 36 homens e 32 mulheres. Eram estrangeiros 55, incluindo 16 africanos. Quanto às doenças mentais dos pacientes falecidos, havia 38 maníacos, 18 dementes, 6 paralíticos e 4 epilépticos.

\section{Formas mentais}

As tabelas das altas e as tabelas dos alienados que permanecem internados em 30 de junho informam as formas mentais encontradas no asilo do Rio de Janeiro, mas é difícil ter uma ideia da proporção de cada uma, pois por um lado, 
os autores adotam uma classificação inusitada, na qual as alucinações, a exaltação maníaca e a mania periódica são relatadas como formas particulares. Além disso, uma grande parte dos pacientes permanece sem diagnóstico.

Encontramos, no entanto, por ordem de frequência: a demência, a mania, a monomania, a lipemania, o alcoolismo, a imbecilidade, a histeria e a paralisia geral.

No Brasil, essas várias formas mentais não apresentam nenhuma característica especial. A paralisia geral é raramente encontrada. O alcoolismo mostra um número relativamente baixo. Esse problema afeta principalmente os negros que consomem aguardente de cana-de-açúcar ou cachaça e nos quais o alcoolismo se traduz pelos mesmos sintomas observados na Europa. As alucinações visuais e auditivas possuem as mesmas características especiais atribuídas a esse problema. Os alcoólatras crônicos sofrem também de ataques epileptiformes. ${ }^{4}$

\section{Nacionalidade}

A média dos estrangeiros tratados no asilo de 1866 a 1874 foi de 64,7 , salvo os africanos. No Brasil, a população estrangeira é representada pelos portugueses, alemães, franceses, italianos, espanhóis e ingleses. Encontramos norte-americanos, argentinos, paraguaios, dinamarqueses e até chineses. De uma maneira geral, podemos afirmar que o número de alienados por nacionalidade corresponde ao número dos seus representantes no país. Os estrangeiros são internados no Hospício Pedro II nas mesmas condições que os brasileiros.

\section{Idade}

De acordo com estatísticas que indicam a idade dos alienados que tiveram alta, que morreram e que permaneceram internados em 30 de junho de 1874, a alienação mental, no Brasil, é mais frequente entre trinta e quarenta anos e mais rara abaixo de vinte anos.

4. A nossa estadia no Rio de Janeiro foi curta demais para poder efetuar observações mais completas do ponto de vista médico. (N. do A.) 
No Brasil, as causas da alienação mental incluem a influência da hereditariedade. O abuso do álcool é comum entre os negros. A influência da temperatura sobre a alienação mental foi observada num relatório de 1869: o número de internações cresceu com o aumento da temperatura. Assim, de setembro a novembro, o número foi de 44 , de dezembro a fevereiro de 1852 , de março a maio de 38 e de junho a agosto, de 1841 . A temperatura média no termômetro centígrado era, de setembro a fevereiro, de $11^{\circ} 35,15^{\circ} 25,27^{\circ} 3,28^{\circ} 1$, $29^{\circ}, 43^{\circ} 7 .^{5}$

Há um número considerável de casos cuja causa é desconhecida devido à falta de informações.

\section{Tratamento}

Os remédios de uso geral para o tratamento da alienação mental são também utilizados pelo asilo do Rio de Janeiro. O brometo de potássio, o iodeto de potássio, o cloral, o cloridrato de morfina, em injeções hipodérmicas, dão os resultados habituais. Um pó vegetal, a espelina, foi utilizado como substituto para o brometo de potássio no tratamento da epilepsia, sem resultados satisfatórios.

A boa instalação dos banhos é bem aproveitada. Os banhos quentes e frios, as duchas, as lavagens e os banhos de vapor são aplicados com frequência. Enfim, os alienistas do Brasil sabem que o trabalho bem organizado é a base do tratamento dos pacientes atingidos pela alienação mental. Em 1869, sobre uma população de 332 doentes (186 homens e 146 mulheres), 83 homens estavam trabalhando em oficinas diversas, no jardim, na cozinha e com tarefas dentro do asilo. Das 146 mulheres, 108 trabalhavam com costura, bordado, tapeçaria e flores artificiais.

Uma parte dessas obras destina-se ao estabelecimento. A outra parte é vendida em benefício dos doentes que trabalham. Há uma biblioteca com alguns livros em vários idiomas.

Existe um sistema de recompensas para os doentes que se mostram dóceis e que respondem bem ao tratamento. Essas incluem objetos que lhes são úteis, seja durante a sua internação, seja depois de sua alta.

5. Essas observações termométricas foram feitas pelo Dr. Ludovino da Sylva, médico-chefe aposentado. (N. do A.) 


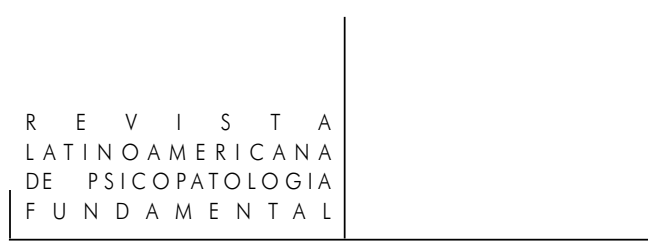

\section{Disciplina. Meios de contenção}

Os meios de repressão autorizados pelo regulamento incluem: a privação de visitas, de passeios e de outros tipos de recreação. Às vezes, a redução dos alimentos, numa proporção prescrita pelo médico, uma estadia na cela-forte e as duchas. A camisa de força é o único meio de contenção que vimos. Ela é utilizada da mesma forma que nos nossos asilos.

\section{Alienados criminosos}

Os alienados criminosos foram recentemente objeto de uma medida especial. Foi criada uma ala exclusiva na casa de detenção para esses infelizes, que consiste de algumas celas que se assemelham às do asilo. Uma dessas celas apresenta uma disposição especial. A parede traseira de madeira é móvel e pode ser manipulada por um mecanismo externo: ela desliza em direção à porta, assim ameaçando o doente. Essa unidade é destinada aos alienados criminosos perigosos. Há também uma sala de reunião ou de trabalho, um refeitório e um banheiro com chuveiros. A área inclui um pequeno gramado. É dessa maneira que os alienados criminosos que cumprem sua sentença, recebem os devidos cuidados que seu estado mental exige.

É uma pena que esta instituição se encontre dentro dos muros de uma prisão, em vez de ser separada, como em Broadmoor, na Inglaterra.

Como se pode julgar por meio desta exposição, o Brasil tem feito muito pelos seus alienados. A capital possui um asilo que, apesar das suas imperfeições, poderia despertar a inveja de mais de uma cidade grande da Europa. Muitos asilos na Itália, para citar apenas aqueles que pudemos visitar, incluindo os de Milão, Florença e Roma, não podem sequer ser comparados ao Hospício Pedro II.

Os prédios são lindos. O granito, o mármore e as madeiras preciosas do Brasil conferem um aspecto verdadeiramente suntuoso. As salas são altas, bem arejadas por meio de numerosas janelas grandes; a água é abundante para as necessidades do atendimento. Tudo é muito limpo, não há maus cheiros. Todas essas qualidades nos fazem lamentar mais ainda que seja apenas a caridade e não a ciência que levou à criação do Hospício Pedro II.

Como já mencionamos, as províncias, particularmente a da Bahia, de Pernambuco e de São Paulo, em breve estarão oferecendo os mesmos cuidados que a Santa Casa da Misericórdia aplica aos seus doentes.

Se a organização do serviço interno ainda deixa a desejar, constatamos através dos relatórios à administração que os médicos possuem um conhecimento 
profundo das reformas necessárias e dos tratamentos aplicados aos alienados.

Com tais elementos, essa parte tão interessante do atendimento hospitalar vai se desenvolver muito no Brasil, desde que ele saiba se proteger do espírito de rotina e das oposições interesseiras que sempre se encontram no caminho do progresso.

Philippe-Marius Rey (1846-1918)

Médico interno dos asilos de alienados do Sena, mais tarde médico-adjunto dos asilos de Vancluse e Ville-Évrard. Entre 1874 e 1878, fez viagens à América do Sul e à Península Ibérica. Publicou a tese "Étude anthropologique sur les botocudos" (1880), sobre os índios botocudos do Espírito Santo, e "Considérations cliniques sus quelques cas d'ataxie locomotrice dans l'aliénation mentale (1875). A partir de 1893 é nomeado médicin-en-chef de asilos em Montdevergue, Aix e Marseille. Falece em 1918, com o título de "médico honorários dos asilos públicos de alienados". 